\title{
A ficcionalização do eu em Bom dia camaradas, de Ondjaki
}

\author{
Ana Beatriz Matte Braun ${ }^{1}$
}

RESUMO: Procura-se neste trabalho investigar a representação do eu no romance Bom dia camaradas, de Ondjaki, refletindo sobre as relações entre os gêneros biográfico e autobiográfico. Busca-se, ainda, examinar como a identidade do narrador/personagem é mostrada na narrativa, discutindo a influência do peritexto e de outros elementos externos à narrativa sobre as possíveis leituras do texto.

ABSTRACT: Our search in this work is to investigate the representation of the self in the novel Bom dia camaradas, by Ondjaki, reflecting on the relationship between the biographical and the autobiographical genres. Our aim is also to examine how the narrator/character's identity is shown in the narrative. Also, we aim at discussing the possible influence of peritext and other elements, external to the narrative, on the readings of the text.

PALAVRAS-CHAVE: Autobiografia; Identidade; Literatura africana.

KEYWORDS: Autobiography; Identity; African literature.

Este artigo tem como objetivo discutir algumas das relações entre autobiografia e ficção por meio da análise do romance Bom dia camaradas, do angolano Ondjaki. Busca-se refletir acerca das formas de ficcionalização do eu no romance, assim como a inserção desse sujeito em um determinado momento histórico. Ao analisar como a identidade do narrador/personagem se manifesta na narrativa, pretende-se observar se e como o romance transita entre ficção, autobiografia e/ ou romance memorialístico, e de que maneira a contribuição do leitor pode modificar as leituras do texto.

Ondjaki nasceu em Luanda em 1977. Seu primeiro livro, publicado em 2000, é de poesia. No ano seguinte, lança Bom dia camaradas, romance narrado por um jovem morador de Luanda. A narrativa mostra, por intermédio de um

1 Doutoranda em Estudos Literários pela Universidade Federal do Paraná. Email: anabeatrizbraun@yahoo.com.br. 
narrador em primeira pessoa, as contradições e dificuldades da vida cotidiana da Angola pós-independência e ainda em guerra civil: a convivência das crianças com a violência brutal - por vezes banalizada, por outras, mitificada; as peculiaridades e contradições de um país em busca da reconstrução identitária. A presença da voz do jovem ou da criança é recorrente na obra de Ondjaki: o mesmo ocorre na coletânea de contos Os da minha rua. Apesar da aparente inocência e inexperiência das vozes infantis, identifica-se a presença de uma ideologia que parece ver a jovem nação angolana dos anos 80 como se em estágio de amadurecimento, assim como as personagens do autor.

Bom dia camaradas apresenta uma natureza híbrida, na qual o relato autobiográfico se confunde com a ficção e/ou vice-versa. Relativizadas as fronteiras entre os gêneros, abrem-se novas possibilidades interpretativas e diferentes formas de perceber o texto literário. Enquanto o enredo se apoia em uma base real, o cotidiano dos habitantes de Luanda na década de 1980, os eventos e personagens têm muito mais liberdade para transitar e cruzar as fronteiras do ficcional, podendo ser moldados e manipulados de acordo com os pressupostos que a narrativa deseja imprimir. Assim, é possível afirmar se há mecanismos internos que nos permitem afirmar que o romance é autobiográfico? Se sim, quais? Como estabelecer a identidade do autor e do narrador/personagem? O romance pode ser lido como sendo de memória? Que influência os elementos extratextuais, ou peritexto, exercem sobre o leitor do romance?

Lejeune (2008) afirma que a diferença entre a autobiografia e o romance repousa em aspectos que são externos ao texto, pois o autobiográfico pressuporia um contrato de leitura. O leitor precisaria acreditar, ou aceitar, que o autor cujo nome está identificado na capa do livro é o mesmo indivíduo que narra. Esse narrador compromete-se a dizer a verdade; se não fosse assim, teria preferido escrever ficção. Acreditando que lerá fatos verídicos narrados pelo indivíduo que os viveu, o leitor determina o gênero e o modo de recepção do texto. A experiência individual do leitor com a obra (devendo ser entendida não 
apenas como texto, mas como o objeto livro propriamente dito), portanto, importa: é a partir dessa relação obra/leitor, estabelecida no momento em que o livro chega às mãos do indivíduo, que a construção do significado da leitura começa a se constituir.

Assim, julgamos ser importante mencionar alguns detalhes a respeito da edição do romance Bom dia camaradas analisada neste artigo. Editada pela editora Ndjira, em 2003, é composta por 138 páginas escritas. Conta também com capa, folha de guarda, contraguarda, folha de rosto e orelha, cujo conteúdo transcreve-se abaixo:

infância é um antigamente que sempre volta.

este livro é muito isso: busca e exposição dos momentos, dos cheiros e das pessoas que fazem parte do meu antigamente, numa época em que angola e os luandenses formavam um universo diferente, peculiar. tudo isso contado pela voz da criança que fui; tudo isto embebido na ambiência dos anos 80: o monopartidarismo, os cartões de abastecimento, os professores cubanos, o hino cantado de manhã e a nossa cidade de luanda com a capacidade de transformar mujimbos em factos, todas estas coisas, mais o camarada antónio... esta estória ficcionada, sendo também parte da minha história, devolveu-me memórias carinhosas, permitiu-me fixar, em livro, um mundo que já é passado, um mundo que me aconteceu e que, hoje, é um sonho saboroso de lembrar.

ondjaki

Após a folha de rosto, há uma dedicatória:

ao camarada antónio

a todos os camaradas cubanos

também para esses meus incríveis companheiros escolares: bruno b., romina, petra, romena, catarina, aina, luaia, alí, filomeno, cláudio, afrik, kiesse, helder, bruno "viola", murtala, io, tandu, fernando,márcia, carla "scooby", enoch, mobutu, felizberto, eliezer, guiguí, filipe, manú, vanuza, hélio, delé, "sérgio cabeleira", e todos os outros que estão incluídos nestas vivências mas cujos nomes o tempo me roubou (e os nomes verdadeiros que deixei nesta estória são para vos homenagear, só isso)

Em seguida, há uma epígrafe dedicada a Angola e, na página seguinte, marcando o início do primeiro capítulo, outra epígrafe: um trecho de "Cultuando musas", de Óscar Ribas. Mais um trecho da mesma obra aparece na 
página 95, anunciando o início do segundo capítulo.

Um leitor que decida ignorar o conteúdo das orelhas, lendo apenas a dedicatória e as epígrafes, que não saiba dados biográficos do autor da obra, e que, enfim, conte com poucas informações extratextuais acerca do contexto de produção do romance, poderá tomar a narrativa como sendo ficcional? Pensamos que não será difícil fazê-lo, se considerarmos que esta edição da Ndjira apresenta a palavra "romance" escrita logo abaixo do título do livro.

Uma análise que abranja elementos intra e extratextuais, assim, nos possibilita perceber de que forma uma narrativa se conecta com seu peritexto e com o conhecimento de mundo do leitor. Segundo Genette (LUCAS, 2011), o conceito de transtextualidade seria a forma como nós, leitores, percebemos o texto e como o relacionamos com uma rede textual maior. Genette contribui para a teoria da recepção porque pensar em transtextualidade pressupõe pensar em competência do leitor e nas circunstâncias históricas que determinam a recepção de um texto:

Para Genette, os textos sempre se inserem numa rede de relações textuais ora visíveis ora invisíveis, e que influenciam (n)a leitura. A competência do leitor está no fato de conseguir, dentre outros aspectos inerentes do ato da leitura, perceber se e como um texto está relacionado com um outro. A percepção ou não dessa ligação transtextual não impede a leitura, apenas proporciona uma leitura diferente (LUCAS, p.116).

Denomina-se paratexto o acompanhamento de um texto em relação a outro, como títulos, nome do autor, prefácio, posfácio, epígrafe, dedicatória e outros cuja função seria, segundo Jouve (2004), orientar a leitura e construir sua recepção. Contudo, há hierarquias e relações de poder entre tais textos. Os elementos paratextuais não são mais importantes do que a obra em si, já que ela funciona sem o paratexto, ao passo que este sem a obra é sempre incompleto. cuja função seria, segundo Jouve (2004), orientar a leitura e construir sua recepção. Contudo, há hierarquias e relações de poder entre tais textos. Os elementos paratextuais não são mais importantes do que a obra em si, já que ela funciona sem o paratexto, ao passo que peritexto (essencialmente autoral, tal como título, subtítulo, dedicatórias, etc) e epitexto (pertencente aos editores, 
como por exemplo capa, catálogos, inserção numa coleção, etc). Todos estes elementos influenciam não apenas a recepção do texto, mas também como será lido e interpretado.

No caso de Bom dia camaradas, é possível que o conhecimento sobre os elementos paratextuais interfira na forma como a narrativa é lida. Mais ainda, ter informações acerca da identidade do autor pode vir a influenciar a decisão do leitor de tomar a obra como ficcional ou um relato de memória. Na página 88 da edição aqui analisada, uma personagem nomeada Ndalu aparece e conta a sua versão para um fato anteriormente ocorrido na narrativa. Para um leitor atento, o aparecimento da personagem chamará atenção, visto que tal nome inexistia até então na narrativa. E, talvez, seja ainda mais surpreendente para o leitor perceber, ao comparar o relato dessa 'nova' personagem com os fatos ocorridos na narrativa, que Ndalu é, na verdade, o narrador.

Ora, pode-se dizer que é um tanto incomum que o nome do narrador, o protagonista com o qual todas as personagens interagem, apareça apenas nos momentos finais da narrativa, visto que o romance não dá espaço para que outras personagens tenham destaque. Tudo o que sabemos e todos os acontecimentos ocorrem em função do narrador. É digna de nota, deste modo, a constatação de que a narrativa guarda para seus momentos finais tal revelação para o leitor. E a questão da nomeação do narrador passa a adquirir outra significação quando o leitor descobre, caso venha a procurar dados biográficos do autor, que o nome de batismo de Ondjaki é Ndalu de Almeida. Neste momento, o leitor pode se dar conta de que o romance poderá ser lido de outros modos, como autobiografia ou romance de memória, já que há identificação, ainda que indireta, entre o nome do autor e o nome da personagem que narra.

Em outras palavras, saber que o Ondjaki é o pseudônimo de Ndalu de Almeida e ler a orelha do livro pode transformar o romance de ficção em autobiografia. Estabelece-se a identidade do narrador no mundo real e passa-se a dar mais credibilidade ao seu relato, pois ele perde o status de ficcional e passa a ser lido como real. Ao mesmo tempo, o fato de o autor afirmar na orelha 
do livro que o romance é uma "estória ficcionada" deixa o leitor em dúvida sobre quais fatos de fato aconteceram e quais foram ficcionalizados. Assim, enquanto a ambiguidade sobre a veracidade dos fatos cresce, cresce também o poder do leitor, na medida em que é ele quem pode definir quais os acontecimentos que ocorreram de verdade e quais foram ficcionalizados pelo autor.

Devemos lembrar, portanto, que o gênero autobiográfico é uma deturpação do real. Apesar de pretender ser um relato verídico de acontecimentos da vida de um determinado indivíduo, a autobiografia não diz necessariamente como os fatos ocorreram, mas sim como ocorreram sob o ponto de vista desse indivíduo. Em vista disso, é uma forma híbrida de expressão, pois seu discurso, repleto de subjetividade, pode ser testemunhal, documental ou ficcional. É igualmente caracterizada pelo dualismo, na medida em que pode aproximar-se mais ou menos da ficção. Apesar disso, o agente que fala, o eu do texto autobiográfico, a princípio tem caráter real, já que aquele que escreve falaria sobre si mesmo e não sobre alguém inventado (AMORIM apud NIGRO; BUSATO; AMORIM, 2010, p.45).

Assim:

Romances que adotam a forma do relato autobiográfico parecem situar-se, por isso mesmo, nessa mesma espécie de zona de indefinição de fronteiras entre ficção e realidade, entre memória e invenção, entre autor empírico e narrador textual. Se na autobiografia verídica a identificação autor-narradorpersonagem é assumida (e a indefinição de fronteiras, quando existe, é quase sempre involuntária), no romance autobiográfico a identificação não se afirma: ao contrário, o que o romance faz é separar autor e narrador-personagem, e busca justamente aquela indefinição, porque interessa à obra inverter a polaridade da expressão: na autobiografia, a ficção invade a subjetividade do eu não ficcional contra a sua vontade, e pode levar o leitor a tentar identificar os erros e enganos cometidos pelo autobiógrafo; no romance, essa subjetividade é trazida para a ficção, como forma de inserir na ficção da obra a realidade histórica de que participam escritor e leitor, que busca então estabelecer as similitudes entre a realidade histórica e o mundo ficcional. Essa ambiguidade que caracteriza as relações entre autobiografia e romance continua a ser um ponto de discussão, obrigando o leitor a um exercício constante de 
desautomatização. (AMORIM, apud NIGRO; BUSATO; AMORIM, p. 46).

O relato autobiográfico seria uma tentativa, por parte daquele que escreve, de buscar explicações para questões presentes. Partindo de um problema posto na esfera individual, a busca acaba incorporando elementos do meio histórico-social no qual o autor se insere. Logo, rememorar o passado poderia ter como objetivo resolver questões do tempo presente, mas cujas respostas se encontram no passado. Ou, como pergunta Sarlo (2007, p. 24), haveria outro sentido em reviver a experiência passada sem necessariamente tentar compreendê-la?

Ainda de acordo com Lejeune, devemos situar os problemas da autobiografia em relação ao nome próprio: um pressuposto do gênero é que haja igualdade entre o nome do autor que aparece na capa com o nome do narrador. Já foi dito que, em Bom dia camaradas, o nome do narrador aparece somente uma vez, quando cada personagem está narrando o que viu enquanto fugiam do que acreditavam ser a visita do Caixão Vazio - uma suposta gangue armada que aterrorizava as escolas de Luanda. A possibilidade da visita do Caixão Vazio atemoriza todos os alunos, deixando-os em estado de alerta. Um certo dia, vista a aproximação de um veículo desconhecido, todos fogem da escola, com medo de que os bandidos estivessem em tal carro. A confusão durante a fuga é enorme, e Ndalu consegue correr com a colega Romina para um local seguro. $\mathrm{O}$ acontecimento tem tamanha importância na vida dos jovens que repercute ainda após vários dias - o que faz com que o narrador dê a oportunidade para que todos apresentem sua perspectiva do ocorrido, cedendo a narrativa a outras vozes. É nesse momento quando um narrador onisciente surge, que o leitor descobre que o nome do narrador é Ndalu. Logo após a última fala, de Romina, Ndalu reassume a posição de narrador, não tendo mais seu nome mencionado.

Nesse sentido, parece que a identificação entre autor e narrador não é importante - como se narrar os acontecimentos fosse mais significativo do que estabelecer a identidade do narrador. Por outro lado, a informação contida no 
peritexto, na orelha do livro e a dedicatória, dão margem para o leitor pensar que há intenção de que a identificação ocorra. Além disso, o leitor que acessar a página oficial do autor na internet encontrará fotos de crianças, identificadas como personagens de Bom dia camaradas e também de Os da minha rua. Ou seja, a ambiguidade existe não só quanto à identidade do narrador, mas também quanto ao gênero do romance. Se internamente à narrativa não há elementos suficientes que nos permitem afirmar que o romance seja autobiográfico, por outro lado, os elementos do peritexto contribuem para que o leitor leia o texto como sendo autobiográfico. Contudo, somente o leitor que voluntariamente procurar essas informações chegará a essa segunda constatação.

Conforme afirma Amorim (apud NIGRO; BUSATO; AMORIM, p. 53),

(...) a focalização autodiegética permite algumas modulações importantes, que podem ser reunidas, grosso modo, em dois grandes grupos: os romances que adotam a forma do diário íntimo e os que adotam a forma da autobiografia em primeira pessoa. Em ambos ocorre a duplicação do eu referida acima: há um eu-instância narrativa, responsável pela enunciação, e um eu-agente diegético, que participa dos eventos narrados.

Ainda segundo ele, a utilização do discurso autobiográfico implicaria na identificação entre narrador e protagonista, como sujeito e objeto do discurso. Contudo, o eu sujeito, localizado em um tempo futuro em relação ao eu objeto, assume um papel de maior importância perante o leitor por ter a capacidade de colocar-se em uma posição de superioridade. O narrador sabe o que aconteceu no passado, e sabe as consequências de tais ações em sua vida. Além disso, sabe que o que conta deve de alguma forma conectar-se com o presente da narrativa, explicar algo que esteja por merecer esclarecimento. Estabelece-se, portanto, uma duplicidade discursiva, "temporal e de identidade; mas, ao nível da linguagem, só o primeiro é identificável, pois o eu permanece o índice tanto do narrador quanto do herói" (AMORIM, apud NIGRO; BUSATO; AMORIM, p. 56).

Bom dia camaradas, enquanto narrativa limitada ao campo mental de uma só personagem, apresentaria ao leitor uma visão única dos acontecimentos vividos, a partir de um ponto de vista fixo, que pode ser tomado como ficcional 
ou não. Assim, a questão da identidade do nome perde força, cedendo lugar à representação da experiência. Se o uso do discurso rememorativo dá credibilidade ao relato, já que um narrador que pode ser identificado como o autor empírico do texto narra certos acontecimentos de sua vida pessoal passada, por outro lado, o aparente desinteresse em enfatizar a associação entre narrador e autor parece indicar que essas experiências podem ser despersonalizadas e assumidas por qualquer jovem que cresceu na Angola dos anos 1980. O discurso individual é o meio utilizado para que o leitor possa se confrontar com temas mais abrangentes, tais como o papel do indivíduo naquela sociedade e os efeitos do momento histórico sobre a formação do caráter de uma geração. Por conseguinte, vê-se o Ndalu narrador como uma figura ficcional, como uma construção discursiva que enuncia a experiência de uma coletividade.

Segundo Sarlo (2007), a valorização da subjetividade promovida na pósmodernidade deu força à ideia de que se pode ler no relato individual muito mais do que a expressão solitária de uma única consciência, mas sim a vivência de um indivíduo cuja identidade, historicamente definida, expressa as angústias e questionamentos de uma determinada época. Se a formação das identidades depende do meio no qual se inserem, pode-se ver uma dimensão coletiva na voz individual e historicidade no testemunho do narrador de Bom dia camaradas, ficcional ou não.

\section{REFERÊNCIAS}

JOUVE, Vincent. A leitura. São Paulo: Editora UNESP, 2002.

LEJEUNE, Philippe. O pacto autobiográfico: de Rousseau à internet. Belo Horizonte: Editora UFMG, 2008.

LUCAS, Ricardo Jorge de Lucena. Genette, Gérard. "Paratexts - Thresholds of interpretation". Revista de Letras, n. 23, v. 1-2, jan-dez/2001. Disponível em www.revistadeletras.ufc.br/r123Art19.pdf. Acesso em: 04 mai. 2011.

NIGRO, Claudia M. C.; BUSATO, Susana; AMORIM, Orlando Nunes de (orgs.). 
Literatura e representações do eu: impressões autobiográficas. São Paulo: Ed. UNESP, 2010.

ONDJAKI. Bom dia camaradas. Editorial Ndjira, 2003.

SARLO, Beatriz. Tempo passado. Cultura da memória e guinada subjetiva. São Paulo: Companhia das Letras; Belo Horizonte: UFMG, 2007. 